meteorological services".

The journal is firmly based in the European context. Of the 40 articles in the first volume, only three originate outside Europe, and all but eight are concerned with regions inside the continent. Given that North American counterpart journals exist, the decision to focus on Europe is wise. It also allows scope to fulfil a need within the European research community: following the example of Bulletin of the American Meteorological Society, news of forthcoming meetings, calls for papers and conference reports are published, along with letters and book reviews.

By comparison with other journals in the field of meteorology, the papers are short. But because some (perhaps all) papers in the first two numbers are based on presentations at the First European Conference on Applications of Meteorology, it is perhaps too early to judge quantity and quality. Production standards are high and several papers include colour illustrations. The price is typical for a journal of this kind.

There is some overlap with existing journals. Particularly in the later numbers of the first volume, papers appear on 'downscaling' from coarse-resolution climate models, and on mesoscale and synoptic events. These do not really fall within the area of applied meteorology. The risk is twofold: that these papers may be overlooked in a literature search and that the journal will become just another outlet for papers on standard meteorological topics. Given that there is a clear niche to fill, it would be a pity to dilute the content in this way. Provided that the journal is faithful to its stated aims, it should fulfil a real need and find a ready market.

Jean Palutikof is at the Climatic Research Unit, University of East Anglia, Norwich NR4 7TJ, UK.

\section{The unpredictable Earth}

\section{David Bercovici}

Nonlinear Processes in Geophysics. Managing editor Arne K. Richter. European Geophysical Society. 4/yr. DM198 $\$ 130$ (institutional); DM90, $\$ 60$ (members).

AT the risk of offending (as many) particle physicists (as possible), I will begin with the bold contention that there is no more universal or fundamental science than the study of nonlinear and complex systems. It has countless applications in, for example, climate variations, plate tectonics, population dynamics, weather prediction, cardiac fibrillation, earthquakes, stock prices and

\title{
Journals also submitted for review
}

The following is a list of journals received that were eligible for review but which for one reason or another are not covered in the supplement. The list does not include journals sent in that had not published enough titles to be considered.

Automated Software Engineering (Kluwer)

Chemical Technology Europe (VCH)

Clinical and Diagnostic Laboratory Immunology (American Society for Microbiology)

Energy for Sustainable Development

(International Energy Initiative)

Engineering Failure Analysis (Pergamon)

European Journal of Plant Pathology (Kluwer)

The Global Atmosphere and Ocean System (Gordon and Breach)

International Journal of Microcirculation (Karger)

Journal of Endotoxin Research

(Churchill Livingstone)

probably the formation of life itself.

Nonlinear processes are seen in the dynamics of the Earth's many spheres, from the magnetosphere to the atmosphere and from the ocean to the Earth's core (which, to complete the circle, generates the magnetosphere). So the launch of Nonlinear Processes in Geophysics is certainly timely and appropriate.

But can a field as interdisciplinary as nonlinear science still be interdisciplinary if it concentrates on the Earth sciences? The answer is an unequivocal 'yes'. The geosciences are essentially founded on the application of mathematics, physics, chemistry and biology to our natural environment. Nonlinear Processes in Geophysics largely succeeds in treating these basic fields with as much variety as in a comparable but more general journal such as Nonlinearity. The journal's offerings so far cover plankton population dynamics, climate variations, oceanic, atmospheric and geophysical fluid dynamics, analysis of radiocarbon dating, earthquakes, topography, the magnetosphere and rainfall. But even with this impressive list of topics, the equitable representation of disciplines still needs some work. Nearly two-thirds of the contributions deal with the atmosphere and ocean. Although the first article in the journal concerns plankton dynamics, it is so far the only paper with a biological twist, a likely consequence of the use of the word 'geophysics' in the journal's title instead of 'geosciences'. But some classical 'geophysical' fields (namely those involving everything beneath the Earth's surface, such as magma and melt processes, mantle convection and especially the core dynamo) are conspicuously absent.

Nevertheless, the journal shows great potential for offering a truly interdiscipli-
Journal of Enhanced Heat Transfer (Gordon and Breach)

Microcirculation: The Official Journal of the Microcirculatory Society, Inc.

(Chapman and Hall)

Psychology Crime and Law (Harwood Adademic)

Reliability, Quality and Safety Engineering (World Scientific)

TB and HIV Quarterly (Sid Alerte Internationale)

Transgenics: Biological Analysis Through DNA Transfer (Harwood Academic)

VLSI Design: An International Journal of Custom-Chip Design, Simulation, and Testing (Gordon and Breach)

Wavelength: The Journal of Science Society and the Media

(University of the West of England) International Journal of Uncertainty, Fuzziness and Knowledge-Based Systems (World Scientific)

nary approach. It allows researchers and students alike to recognize themes common to different articles, such as concepts of multifractal analysis and self-organized criticality applied to atmospheric turbulence, earthquakes landslides, rainfall and geomorphology.

The overall scientific quality and clarity of the papers are reasonably high, although some of the contributors could have been encouraged to write for a broader audience than just their colleagues. More review articles (I counted only one) would help to foster such interdisciplinary communication and comprehension.

The journal offers good value for both subscribers and contributors (there are no page charges); production quality is reasonable and the layout is fairly uniform in appearance; and time from submission to acceptance of papers is a fairly average 6-9 months.

Scientists (like other humans) enjoy a fine whine, and one of their favourite complaints is about the proliferation of journals. No one denies that the excessive number of articles and journals prohibits busy scientists from keeping abreast of the literature. But it is important for scientists to experiment with as many different combinations and permutations of disciplines as possible. New journals provide an important platform for such experimentation. In offering fresh approaches, Nonlinear Processes in Geophysics is set on a promising path.

David Bercovici is in the Department of Geology and Geophysics, School of Ocean and Earth Sciences and Technology, University of Hawaii, 2525 Correa Road, Honolulu, Hawaii 96822, USA. 